\title{
Construction of a novel Pichia pastoris strain for production of xanthophylls
}

\author{
José Miguel Araya-Garay ${ }^{1}$, José M Ageitos ${ }^{1}$, Juan A Vallejo ${ }^{1}$, Patricia Veiga-Crespo ${ }^{1,2}$, Angeles Sánchez-Pérez ${ }^{3}$
} and Tomás G Villa ${ }^{1,2^{*}}$

\begin{abstract}
In this study, we used the yeast carotenogenic producer Pichia pastoris Pp-EBIL strain, which has been metabolically engineered, by heterologously expressing $\beta$-carotene-pathway enzymes to produce $\beta$-carotene, as a vessel for recombinant astaxanthin expression. For this purpose, we designed new P. pastoris recombinant-strains harboring astaxanthin-encoding genes from carotenogenic microorganism, and thus capable of producing xanthophyllic compounds. We designed and constructed a plasmid (pGAPZA-WZ) containing both the $\beta$-carotene ketolase (crtW) and $\beta$-carotene hydroxylase (crtZ) genes from Agrobacterium aurantiacum, under the control of the GAP promoter and containing an AOX-1 terminator. The plasmid was then integrated into the P. pastoris Pp-EBIL strain genomic DNA, producing clone Pp-EBILWZ. The recombinant P. pastoris (Pp-EBILWZ) cells exhibited a strong reddish carotenoid coloration and were confirmed, by HPLC, to produce not only the previous described carotenoids lycopene and $\beta$-carotene, but also de novo synthesized astaxanthin.
\end{abstract}

Keywords: Pichia pastoris, Carotenoids, $\beta$-carotene, Astaxanthin

\section{Introduction}

Carotenoids are natural lipid-soluble pigments produced primarily by bacteria, algae and plants. These pigments are in part responsible for the wide variety of colors seen in nature. In some organisms, carotenoids such as $\beta$-carotene are modified with oxygencontaining functional groups, thus creating xanthophylls such as astaxanthin.

Astaxanthin is an abundant carotenoid found in marine animals, including salmonids and crustaceans (Miki et al. 1982; Wade et al. 2005) and is a commonly encountered keto-carotenoid in certain algae, many invertebrates and fish. The use of astaxanthin as colorant in aquaculture, especially as feed supplement in farmed trout, salmon and prawns, is necessary to obtain the red-pink coloration present in their wild counterparts, since neither fish nor prawns are capable of de novo carotenoid synthesis. Incorporation of astaxanthin into the fish and prawn feed not only

\footnotetext{
* Correspondence: tom.villa@gmail.com

'Department of Microbiology, University of Santiago de Compostela,

Santiago de Compostela, Spain

${ }^{2}$ School of Biotechnology, University of Santiago de Compostela, Santiago de Compostela, Spain

Full list of author information is available at the end of the article
}

increases their nutritional value, but also considerably enhances their appeal to customers and hence their commercial value.

Astaxanthin has attracted commercial interest not only in its role as a pigment, but also as a potent antioxidant capable of delaying aging and the onset of degenerative diseases in animals (Hix et al. 2004; Kurihara et al. 2002; Neuman et al. 2000). Furthermore, epidemiological and experimental studies have suggested that astaxanthin also possesses anticarcinogenic and antitumor activities (Neuman et al. 2000; Bertram \& Vine 2005; Kozuki et al. 2000), hence astaxanthin's relevance is progressively increasing in the pharmaceutical and cosmetic industries.

The cluster genes responsible for the synthesis of xanthophylls have been isolated from the marine bacterium A. aurantiacum. Analysis of its nucleotide sequence revealed five open reading frames, designated as genes crtW, crt $Z$, crt $Y, \operatorname{crtI}$, and $c r t B$, respectively (Misawa et al. 1995) and functionally analyzed in $E$. coli (Misawa et al. 1995). $\beta$-carotene ketolase ( $c r t W$ genes) converts $\beta$-carotene to canthaxanthin, with echinenone as an intermediary step; whereas $\beta$-carotene hydroxylase ( $c r t Z$ genes) mediates the conversion of $\beta$-carotene to 


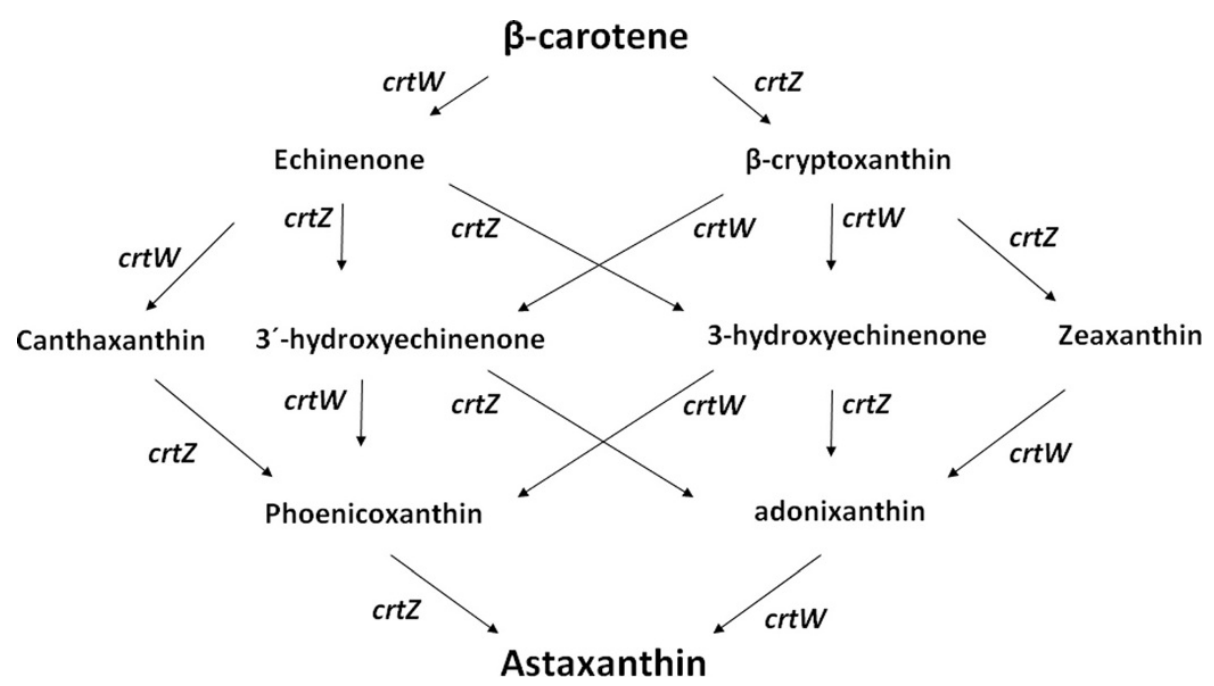

Figure 1 Schematic diagram of astaxanthin biosynthetic pathways and possible intermediates in Agrobacterium. aurantiacum, modified from Misawa et al. 1995.

zeaxanthin, via $\beta$-cryptoxanthin. As seen in Figure 1, the crt $W$ and crt $Z$ gene products, in combination, catalyze all the necessary steps for the conversion of $\beta$-carotene into astaxanthin (Figure 1).

A variety of carotenoid biosynthesis genes that produce astaxanthin have been isolated from various sources, including the yeast Xanthophyllomyces dendrorhous (Johnson et al. 1980), the green alga Haematococcus pluvialis (Bubrick 1991), the gram-positive bacterium Brevibacterium linens (Krubasik \& Sandmann 2000), and the marine bacterium Paracoccus haeundaensis (Lee et al. 2004), and the function of their gene products has been determined (Kurihara et al. 2002; Krubasik \& Sandmann 2000; Armstrong et al. 1989; Harker \& Hirschberg 1998; Harker \& Hirschberg 1997; Misawa et al. 1990; Verdoes et al. 1999).

Recombinant carotenoid biosynthesis was successful, by introduction and modification of heterologous carotenogenic genes, in originally non-carotenogenic yeasts, such as Saccharomyces cerevisiae (Lange \& Steinbüchel 2011; Ukibe et al. 2009; Verwaal et al. 2007; Yamamo et al. 1994), both $S$. cerevisiae and Candida utilis (Misawa \& Shimada 1998), C. utilis (Miura et al. 1998; Misawa \& Shimada 1998), P. pastoris (Araya-Garay et al. 2012; Bhataya et al. 2009), and the filamentous fungus Mucor circinelloides (Papp et al. 2006).

In the present work, we successfully modified the carotenoid production of $P$. pastoris Pp-EBIL strain by incorporating in its genome the $c r t W$ and $c r t Z$ genes from the marine bacterium $A$. aurantiacum. This resulted in a recombinant $P$. pastoris which synthesized astaxanthin as well as pathway intermediates such as lycopene, $\beta$-carotene and canthaxanthin.

\section{Materials and methods}

\section{Strains, plasmid and culture conditions}

Plasmid pGAPZ $\alpha$ A was purchased from Invitrogen Corporation (Carlsbad, CA, USA), whereas the $\beta$-carotene producer Pp-EBIL strain of $P$. pastoris was constructed as previously described (Araya-Garay et al. 2012).

$P$. pastoris cells were grown in YPD medium supplemented with Zeocin $(100 \mu \mathrm{g} / \mathrm{mL}$; Invitrogen $)$ and incubated at $30^{\circ} \mathrm{C}$, in a rotary shaker at $200 \mathrm{rpm}$ for $72 \mathrm{~h}$. Escherichia coli TOP10 cells were grown in low salt LB medium at $37^{\circ} \mathrm{C}$ for $12 \mathrm{~h}$, and clones containing plasmid pGAPZ $\alpha A$ were selected by their Zeocin $(25 \mu \mathrm{g} / \mathrm{mL})$ resistance. pGAPZ $\alpha$ A* (a mutant pGAPZ $\alpha A$ missing an AvrII site) was generated by site-directed mutagenesis (Araya-Garay et al. 2012). Genes crtW and crt $Z$ were amplified from the plasmid pAK96K (Misawa et al. $1995)$, which harbors both the $A$. aurantiacum crtW ( $\beta$-carotene ketolase) and $\operatorname{crtZ}(\beta$-carotene hydroxylase) genes, and was shown to mediate the conversion of $\beta$-carotene into astaxanthin in recombinant E. coli cells. This plasmid was a gift from Prof. Misawa (Research Institute for Bioresources and Biotechnology, Ishikawa Prefectural University, Japan). Amplification of the above mentioned genes was carried out using 5/ primers that contained a restriction $S f u I$ site, followed by an optimized Kozak consensus sequence (ATGG), as well as a start codon, and a 3/ primer containing an EcoRI restriction site (Table 1). All DNA ligations were carried out with T4 DNA ligase (New England BioLabs, Beverly, MA, USA), as recommended by the manufacturer. After DNA ligation, the plasmids were transformed into chemically-competent E. coli Top 10 "One shot" (Invitrogen), and grown on low salt Luria-Bertani media 
Table 1 Oligonucleotide primers used in this study for either PCR-amplification or DNA sequencing

\begin{tabular}{|c|c|c|}
\hline Primer name & Primer sequence (5/-3/) & Application \\
\hline Aa-crtW Forward & 5/ AACTATTTCGAAACGATGGCACATGCCCTGCC 3/ & PCR \\
\hline Aa-crtW Reverse & 5/GGAATTCTCAGCGGTGCCCCC 3/ & PCR \\
\hline Aa-crtZ Forward & 5/ AACTATTTCGAAACGATGGCAAATTCCTGATCG 3/ & PCR \\
\hline Aa-crtZ Reverse & 5/ GGAATTCTCACGTGCGCTCCTGC 3/ & PCR \\
\hline pGAP Forward 1 & 5/ GTCCCTATTTCAATCAATGAA 3 I & Sequencing \\
\hline pGAP Forward 2 & 5/ AGATCTIIIITGTAGAAATGTC 3/ & Sequencing \\
\hline AOX-1 Reverse & 5/ GCAAATGGCATTCTGACATCC 3/ & Sequencing \\
\hline
\end{tabular}

(0.5\% Yeast extract, $1 \%$ Tryptone, $0.5 \% \mathrm{NaCl})$ plates containing $25 \mu \mathrm{g} / \mathrm{mL}$ Zeocin. The plates were then incubated overnight at $37^{\circ} \mathrm{C}$ and recombinant colonies selected and grown overnight in low salt LB media containing $25 \mu \mathrm{g} / \mathrm{mL}$ Zeocin.

The Graphical Codon Usage Analyser 2.0 (Fuhrmann et al. 2004) was used for differential codon usage analysis.

\section{Construction of carotenoid expression vectors}

The DNA coding for $c r t W$ was inserted into the SfuI and EcoRI restriction sites of plasmid pGAPZ $\alpha A$, and the same restriction sites were used for inserting $\operatorname{crt} Z$ DNA into pGAPZ $\alpha A^{*}$. The resulting expression vectors were denominated pGAPZA-W and pGAPZA*-Z, respectively and both plasmids lacked the alpha factor (Figure 2). The BamHI-BglII DNA fragment from pGAPZA*-Z was subcloned into the $B a m H I$ site of plasmid pGAPZA-W to generate the pGAPZA-WZ expression vector (Figure 2). All plasmids constructed in this study were subjected to DNA sequencing before use and are shown in Table 2.

\section{Plasmid transformation}

Plasmid pGAPZA-WZ was linearized with the restriction enzyme AvrII (New England BioLabs) and transformed into electrocompetent $P$. pastoris Pp-EBIL cells by electroporation, using a Bio-Rad Micropulser (BioRad Laboratories, Inc Hercules, CA) as described previously (Araya-Garay et al. 2012). Recombinant P. pastoris cells were then selected on YPDS (1\% yeast extract, $2 \%$ peptone, $2 \%$ glucose, and $1 \mathrm{M}$ sorbitol) plates, supplemented with Zeocin $(200 \mu \mathrm{g} / \mathrm{mL})$. The plates were incubated at $30^{\circ} \mathrm{C}$ until colonies were visible $(48-72 \mathrm{~h})$, transferred to room temperature, and incubated for a further $48-72 \mathrm{~h}$. Gene integration into the $P$. pastoris genome was analyzed by PCR, using $P$. pastoris genomic DNA extracted with the Master Pure ${ }^{\mathrm{TM}}$ Yeast DNA Purification Kit (Epicentre Biotechnologies, Madison, WI, USA).

\section{Yeast culture and harvest}

Red (Pp-EBILWZ) P. pastoris colonies, obtained in YPDS agar plates, were selected and grown, for $72 \mathrm{~h}$ at $30^{\circ} \mathrm{C}$, with shaking at $200 \mathrm{rpm}$, in 100 to $500 \mathrm{~mL}$ of YPD (yeast extract $1 \%$, peptone $2 \%$, and glucose $2 \%$ ) media containing $200 \mu \mathrm{g} / \mathrm{mL}$ Zeocin. The cell culture was then harvested, washed with distilled water, centrifuged and lyophilized for $48 \mathrm{~h}$ at $0.1 \mathrm{mbar}$ in a Telstar Cryodos Lyophilizer.

\section{Carotenoid extraction}

Prior to carotenoid extraction, $50 \mathrm{mg}$ of lyophilized yeast cells were incubated in $3 \mathrm{~mL}$ of DMSO, pre-warmed at $55^{\circ} \mathrm{C}$ for $30 \mathrm{~min}$, with strong shaking for $1 \mathrm{~min}$, and then maintained for an extra $30 \mathrm{~min}$ without shaking (Dos Santos et al. 2011). Residual cell-suspension, from each of the above treatments, was extracted with $10 \mathrm{~mL}$ of acetone and vortexed for $5 \mathrm{~min}$ at $4^{\circ} \mathrm{C}$. Extracts were then combined with $5 \mathrm{~mL}$ of hexane and $1 \mathrm{~mL}$ of $0.1 \mathrm{M}$ phosphate buffer, followed by vortexing for $30 \mathrm{~s}$ and centrifugation at $3000 \mathrm{~g}$ for $10 \mathrm{~min}$. This extraction procedure was repeated until both the supernatant and residual cell pellet were colorless. The crude solvent extract thus obtained was then evaporated, under a stream of $\mathrm{N}_{2}$ flow, and kept at $-80^{\circ} \mathrm{C}$ until high performance liquid chromatography (HPLC) analysis. All above treatments were carried out on ice and under dim light conditions, to prevent photo-degradation, isomerization and structural carotenoid changes.

\section{HPLC analysis of carotenoids}

Carotenoid samples were prepared for HPLC by dissolving their cryo-preserved dry extracts in $2 \mathrm{~mL}$ of chlorophorm:metanol:acetone (3:2:1, v:v:v) and filtering them through polycarbonate $0.22 \mu \mathrm{m}$ membranes. HPLC was carried out on a $\mathrm{C}_{30}$ carotenoid column (250 mm x 4,6 mm, $5 \mu \mathrm{m}$; YMC Europe), as previously described (Araya-Garay et al. 2012). Carotenoids were identified by comparing their HPLC retention time and color with commercial standards. The $\beta$-carotene and astaxanthin standards were 


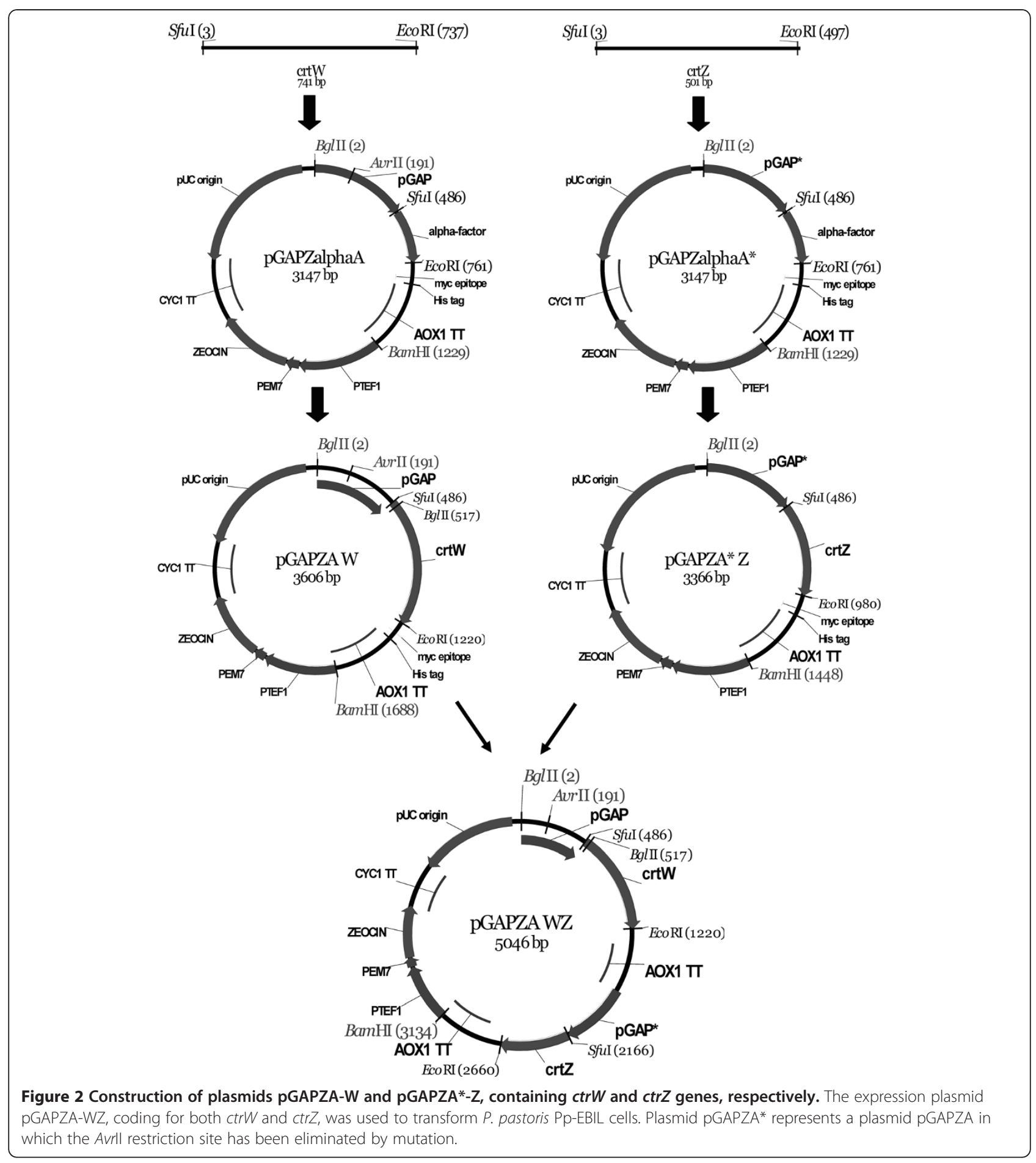

obtained from Sigma-Aldrich (Madrid, Spain). For each elution, a Maxplot chromatogram was obtained, displaying the carotenoid elution profile and its corresponding maximum absorbance wavelength. Qualitative analyses were carried out by comparing the carotenoid profiles obtained with the retention times for the $\beta$-carotene and astaxanthin standards.

\section{Results}

Construction of expression plasmids

The coding regions for genes $\mathrm{crt} W$ and $\mathrm{crt} Z$, from $A$. aurantiacum, were PCR amplified from the plasmid pAK96K (Misawa et al. 1995). The PCR products were then subcloned into the SfuI and EcoRI sites of pGAPZ $\alpha A$, an expression vector containing a constitutive 
Table 2 Summary of the DNA plasmids used and/or constructed in this study

\begin{tabular}{lll}
\hline Plasmid name & Description & Source or reference \\
\hline pGAPZaA & Integrative plasmid for P. pastoris $\left(Z \mathrm{Zo}^{\mathrm{R}}\right)$ & (Invitrogen) \\
pGAPZaA* $^{*}$ & (Araya-Garay et al. 2012) \\
pGAPZA-W & $c r t W$ gene cloned in pGAPZA without a factor & This study \\
pGAPZA*-Z & $c r t Z$ gene cloned in pGAPZA* without a factor & This study \\
pGAPZA-WZ & $c r t W$ and $c r t Z$ genes cloned in pGAPZA & This study \\
\hline
\end{tabular}

GAP promoter and an $A O X-1$ terminator, generating plasmids pGAPZA-W and pGAPZA*-Z (without AvrII site) (Figure 2). The BamHI-BglII fragment from plasmid pGAPZA*-Z was then subcloned into the BamHI restriction site of plasmid pGAPZA-W and the resulting construct integrated into $P$. pastoris Pp-EBIL DNA genome by recombination events. Finally, plasmid pGAPZA-WZ (5046 bp) was designed, constructed and introduced into the yeast P. pastoris to produce astaxanthin (Figure 2).

\section{Characterization of the Pichia pastoris recombinant clones} The wild type $P$. pastoris X-33 yeast cells, shown in Figure 3A, display the typical white color characteristic of this strain. On the other hand, the Pp-EBIL recombinant strain, we used as the base for our transformation, shows an orange color (Figure 3B) typical of a strain producing lycopene and $\beta$-carotene (Araya-Garay et al. 2012). Finally, integration of the plasmid pGAPZA-WZ into the Pp-EBIL genome resulted in yet another visible change in the color of the recombinant cells. The red cultures thus obtained (Figure 3C) are what will be expected from cells capable of de novo production of the carotenoid astaxanthin. The PpEBILWZ recombinant cells were confirmed, by PCR analyses, to contain the six recombinant genes we transformed integrated in their genomic DNA.

\section{HPLC analyses of carotenoids}

To further confirm the nature and composition of the carotenoids produced by the red recombinant $\mathrm{Pp}$ EBILWZ cultures, the photochromic compounds were extracted from the lyophilized cells and analyzed by high resolution liquid chromatography, coupled to a photodiode array detector (HPLC-PDA). These analyses revealed that the Pp-EBIL strain, carrying the plasmid pGAPZA-WZ, did indeed synthesize astaxanthin and this was accompanied by the accumulation of biosynthesis precursors, such as lycopene, $\beta$-carotene and a small amount of canthaxanthin, but no zeaxanthin was detected (Figure 4). The astaxanthin concentration produced by the cultures was $3.7 \mu \mathrm{g}$ per $\mathrm{g}$ of cells (dry weight).

It has now been known for some time (Komar et al. 1999) that synonymous codon substitutions may not always be silent, they can change protein structure and function and can be responsible for low expression of heterologous proteins (recently reviewed by (Angov 2011)). To investigate whether the low astaxanthin production by our recombinant Pp-EBIL strain could be attributed to differences in synonymous codon usage between expression and natural hosts, we used the Graphical Codon Usage Analyser 2.0 (Fuhrmann et al. 2004) to compare codon usage by the expression host ( $P$. pastoris),

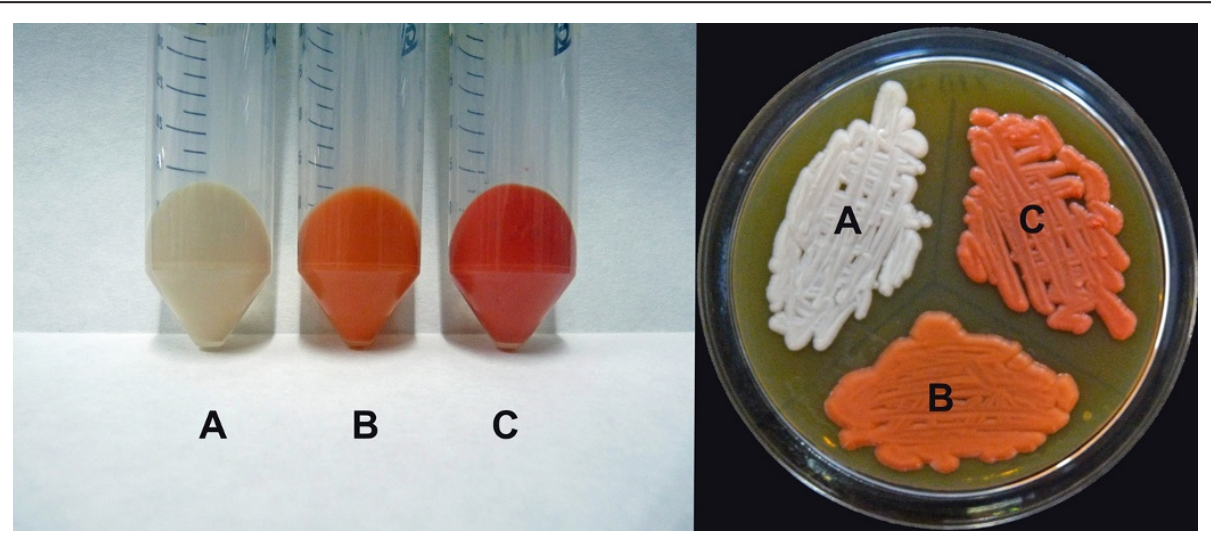

Figure 3 Photographs of $P$. pastoris wet cell pellets (left) and agar plates (right). (A) Non-transgenic culture; (B) Recombinant Pp-EBIL cells producing lycopene and $\beta$-carotene; (C) Recombinant Pp-EBIL strain harboring the plasmid PGAPZA-WZ and producing lycopene, $\beta$-carotene and astaxanthin. The reddish color corresponds to the carotenoids produced by the transgenic cultures. 


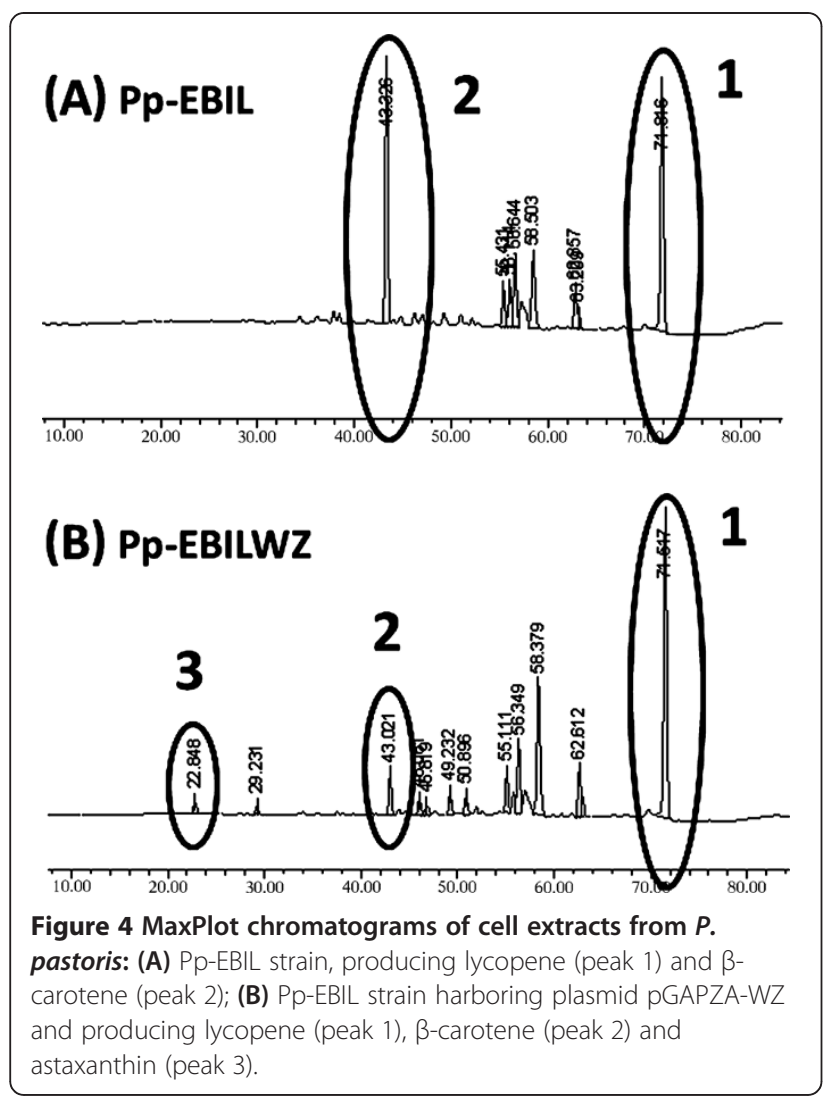

the two natural hosts (E. uredovora and A. aurantiacum) and the fig tree (F. carica). As shown in Figure 5, the codon usage by $E$. uredovora is markedly different (differences ranging from 33.72 to $35.66 \%)$ from that of $P$. pastoris. The difference is even more marked $(\sim 51 \%)$ with $A$. aurantiacum, whereas the fig tree appears to be more closely related to our expression host (only 19.31\% differences).

From the Figure 5 results, it appears that the low astaxanthin production by our recombinant Pp-EBIL strain could indeed be due to differences in synonymous codon usage between $P$. pastoris and the recombinant genes natural hosts, and this is an area we are currently investigating.

\section{Discussion}

Although S. cerevisiae and P. pastoris share considerable genetic similarity that has enabled expression of similar genes and compatibility between vectors, $P$. pastoris has a strong preference for respiratory metabolism. This means that the latter can grow at high cell densities without the accumulation of ethanol, an event that usually occurs in S. cerevisiae (Cereghino et al. 2002) and hinders culture growth and hence protein production. Other advantages of using $P$. pastoris for heterologous protein expression reside on the simplicity of this system, the availability of strong promoters to drive gene expression, and the ability of this system to perform eukaryotic post-translational modifications at low cost (Cregg et al. 2002; Lin Cereghino \& Cregg 2000).

On the other hand, yeasts have several cellular organelles which are physically separated from other cellular components by membrane structures (Karpichev \& Small

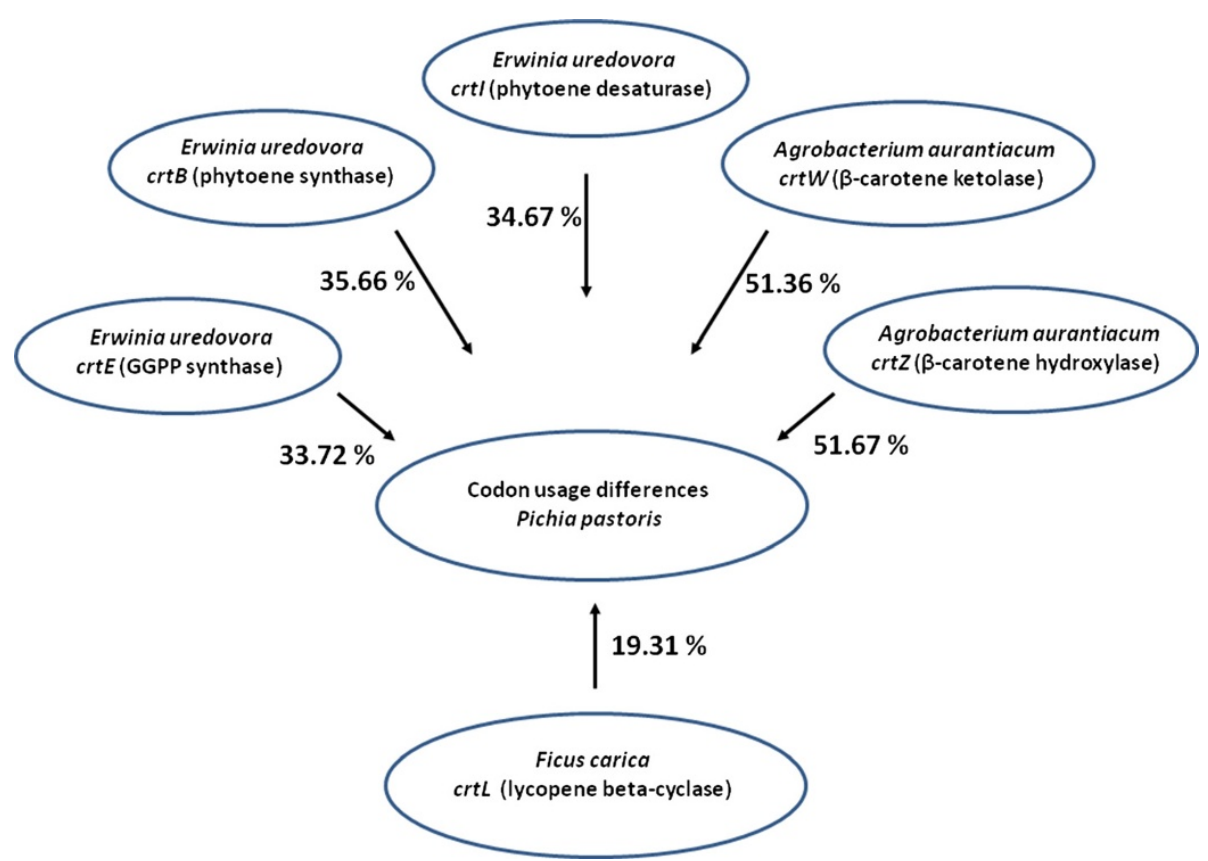

Figure 5 Differences in synonymous codon usage in Pichia pastoris genome, as compared to Erwinia uredovora ctrE, ctrB and ctrl genes, Agrobacterium aurantiacum ctrW and ctrZ genes, and Ficus carica crtL gene. 
2000). The heterologously expressed six enzymes were designed to be randomly distributed in P. pastoris, and both cellular and cytoplasmic membranes can be putative locations for membrane-bound enzymes to settle in (Bhataya et al. 2009). Therefore, since other yeasts such as $S$. cerevisiae and $X$. dendrorhous have similarity on the structural constrains of the cells and they have higher levels of astaxanthin production, we believe that the structural constrains of $P$. pastoris is it not a limit factor for astaxanthin production.

In the present work, we have succeeded in constructing genetically-stable astaxanthin-producing $P$. pastoris strains (Pp-EBILWZ). We achieved this by introducing the carotenogenic genes $\operatorname{crtW}$ ( $\beta$-carotene ketolase) and $\operatorname{crt} Z$ $(\beta$-carotene hidroxylase) into a $\beta$-carotene-producing $P$. pastoris strain (Pp-EBIL) we previously engineered (Araya-Garay et al. 2012) under the control of a GAP promoter.

DNA integration into a GAP locus requires linearization of the expression vectors with $A v r \mathrm{II}$, and there is a recognition site for this restriction enzyme within the coding region of the GAP promoter. To avoid this complication, we removed, by site-directed mutagenesis, the AvrII restriction site within the pGAPZ $\alpha \mathrm{A}$ plasmid thus generating the silent-mutated plasmid pGAPZ $\alpha A^{*}$. This plasmid was further modified by addition of the two crt genes required for the synthesis of astaxanthin from $\beta$-carotene (Figure 2), giving rise to the integrative plasmid we named pGAPZA-WZ. Recombinant plasmid pGAPZA-WZ was then integrated into Pp-EBIL genomic DNA, resulting in the production of yeast cells with a red coloration (Figure 3 ).

To determine the composition of the carotenoids produced by Pp-EBILWZ, this strain was grown for 3 days in liquid culture containing Zeocin $(200 \mu \mathrm{g} / \mathrm{mL})$, and the carotenoid content in the yeast cells analyzed by HPLC. As shown in Figure 4, our recombinant $P$. pastoris strain was indeed capable of synthesizing new xanthophylls, but its astaxanthin production level was below its $\beta$-carotene production. Additionally, the accumulation of astaxanthin metabolic intermediates indicates that the flux through the carotenogenic pathway was not fully efficient. The astaxanthin yield we obtained from our recombinant yeast is lower than those previously reported for heterologous astaxanthin production in $C$. utilis (Miura et al. 1998) with the amounts of $400 \mu \mathrm{g}$ per $\mathrm{g}$ of cells (dry weight) and S. cerevisiae (Ukibe et al. 2009) with $29 \mu \mathrm{g}$ per $\mathrm{g}$ of cells (dry weight); although it is very close to the yield obtained in $M$. circinelloides (Papp et al. 2006) with $3 \mu \mathrm{g}$ per g of cells (dry weight). Whereas in other microorganisms such as $X$. dendrorhous and $H$. pluvialis a significantly higher level of production are observed $(120 \mu \mathrm{g}$ and $114 \mu \mathrm{g}$ per $\mathrm{g}$ of cells [dry weight], respectively). It should be noted that
Pp-EBIL cells accumulated more $\beta$-carotene (339 $\mu \mathrm{g}$ per $g$ [dry weight] of cells) than the total amounts of astaxanthin and $\beta$-carotene in the wild-type cells of $X$. dendrorhous (270 $\mu \mathrm{g}$ per $\mathrm{g}$ [dry weight] of cells). The Pp-EBILWZ had an additional drawback, as its growth was slower than that of the Pp-EBIL strain it originated from.

From the results shown in Figure 5, it appears that the low astaxanthin production by our recombinant Pp-EBILWZ strain could be due to differences in synonymous codon usage between $P$. pastoris and the recombinant genes natural hosts. This codon usage appears to be related to the intracellular availability of each tRNA, whose concentration is relatively proportional to the frequency of its complementary codon coding sequences population. This suggests that the speed of translation and, therefore, carotenoid protein production, may be limited and our recombinant strain cannot achieve high protein expression level for all of the six foreign genes the cells host. It must also be taken into account that the six recombinant genes are all members of the same pathway and are under the same GAP promoter. This could cause metabolic stress in the yeast cells, by limiting the availability of transcription factors required for proper expression of all the pathway proteins. Metabolic overload could be the cause of the slowing down of the cell growth observed in Pp-EBILWZ, as compared with the two strains (Pp-EBIL and P. pastoris $\mathrm{X}-33)$ it originates from.

However, based on the published strategies for improvements in the production of carotenoids described for other organisms, either by over-expression of genes, codon usage optimization or modification of gene members of the pathway, we believe that it is possible to increase our current astaxanthin production levels in P. pastoris to an industrially-relevant yield. One approach worth considering is that reported by Verwaal et al. (Verwaal et al. 2007) and Yuan et al. (Yuan et al. 2006), using mutated cultures and special fermentation conditions in large volumes. This strategy has worked well for $X$. dendrorhous, resulting in a marked increase in astaxanthin production (An et al. 1989).

In conclusion, the results shown here indicate that it is indeed feasible to biosynthesize astaxanthin using the $\beta$-carotene-producing $P$. pastoris strain (Pp-EBIL) here described, although further investigation is required in order to improve the protein yield. This represents a further step in recombinant carotenoid production, and carotenoids, astaxanthin in particular, play an important role in the aquaculture industry and their addition into the fish and prawn feed not only increases their nutritional value, but also considerably enhances their appeal to customers and hence their commercial value. Additionally, there is increasing concern about food security, in particular 
fish and sea food, and aquaculture is progressively replacing shortages in fish catches, caused by overfishing, pollution, climate change and other insults to the marine habitats.

\section{Competing interests}

The authors declare that they have no competing interests.

\section{Acknowledgements}

J. M. A-G. is the recipient of an AECID scholarship from the Spanish Foreign Affairs Ministry. The authors thank Dr. Norihiko Misawa (Research Institute for Bioresources and Biotechnology, Ishikawa Prefectural University) for the gift of plasmid pAK96K, and both the Faculty of Pharmacy and School of Biotechnology for their support throughout this project.

\section{Author details}

'Department of Microbiology, University of Santiago de Compostela, Santiago de Compostela, Spain. ${ }^{2}$ School of Biotechnology, University of Santiago de Compostela, Santiago de Compostela, Spain. ${ }^{3}$ Discipline of Physiology and Bosch Institute, University of Sydney, Sydney, NSW 2006, Australia.

Received: 5 February 2012 Accepted: 11 February 2012

Published: 25 April 2012

\section{References}

An GH, Shuman DB, Johnson EA (1989) Isolation of Phaffia rhodozyma mutants with increased astaxanthin content. Appl Environ Microbiol 55:116-124

Angov E (2011) Codon usage: nature's roadmap to expression and folding of proteins. Biotech J 6:650-659

Araya-Garay JM, Feijoo-Siota L, Rosa-dos-Santos F, Veiga-Crespo P, Villa TG (2012) Construction of new Pichia pastoris X-33 strains for production of lycopene and $\beta$-carotene. Appl Microbiol Biotechnol 93:2483-2492

Armstrong GA, Alberti M, Leach F, Hearst JE (1989) Nucleotide sequence, organization, and nature of the protein products of the carotenoid biosynthesis gene cluster of Rhodobacter capsulatus. Mol Gen Genet 216:254-268

Bertram JS, Vine AL (2005) Biochim Biophys Acta 1740:170-178

Bhataya A, Schmidt-Dannert C, Lee PC (2009) Metabolic engineering of Pichia pastoris X-33 for lycopene production. Process Biochem 44:1095-1102

Bubrick P (1991) Production of astaxanthin from Haematococcus. Bioresour Technol 38:237-239

Cereghino GP, Cereghino JL, llgen C, Cregg JM (2002) Production of recombinant proteins in fermenter cultures of the yeast Pichia pastoris: heterologous protein expression in the methylotrophic yeast Pichia pastoris. Curr Opin Biotechnol 13:329-332

Cregg JM, Cereghino JL, Shi J, Higgins DR (2002) Recombinant protein expression in Pichia pastoris. Mol Biotechnol 16:23-52

Dos Santos RA, da Silva R, Kalii S, Veiga A, de Fernandes J (2011) Different cell disruption methods for astaxanthin recovery by Phaffia rhodozyma. Afr J Biotechnol 10:1165-1171

Fuhrmann M, Hausherr A, Ferbitz L, Schödl T, Heitzer M, Hegemann P (2004) Monitoring dynamic expression of nuclear genes in Clamydomonas reinhardtii by using a synthetic luciferace reporter gene. Plant Mol Biol 55:869-881

Harker M, Hirschberg J (1997) Biosynthesis of ketocarotenoids in transgenic cyanobacteria expressing the algal gene for beta-C-4-oxygenase, crtO. FEBS Lett 404:129-134

Harker M, Hirschberg J, Oren A (1998) Paracoccus marcusii sp. nov., an orange gram-negative coccus. Int J Syst Bacteriol 48:543-548

Hix LM, Lockwood SF, Bertram JS (2004) Bioactive carotenoids: potent antioxidants and regulators of gene expression. Redox Rep 9:181-191

Johnson EA, Villa TG, Lewis MJ (1980) Phaffia rhodozyma as an astaxanthin sources in salmonid diet. Aquaculture 20:123-134

Karpichev IV, Small GM (2000) Evidence for a novel pathway for the targeting of a Saccharomyces cerevisiae peroxisomal protein belonging to the isomerase/ hydratase family. J Cell Sci 113:533-544

Komar AA, Lesnik T, Reiss C (1999) Synonymous codon substitutions affect ribosome traffic and protein folding during in vitro translation. FEBS Lett 462:387-391

Kozuki Y, Miura Y, Yagasaki K (2000) Inhibitory effects of carotenoids on the invasion of rat ascites hepatoma cells in culture. Cancer Lett 151:111-115
Krubasik P, Sandmann G (2000) A carotenogenic gene cluster from Brevibacterium linens with novel lycopene cyclase genes involved in the synthesis of aromatic carotenoids. Mol Gen Genet 263:423-432

Kurihara H, Koda H, Asami S, Kiso Y, Tanaka T (2002) Contribution of the antioxidative property of astaxanthin to its protective effect on the promotion of cancer metastasis in mice treated with restraint stress. Life Sci 70:2509-2520

Lange N, Steinbüchel A (2011) $\beta$-carotene production by Saccharomyces cerevisiae with regard to plasmid stability and culture media. Appl Microbiol Biotechnol 91:1611-1622

Lee JH, Kim YS, Choi TJ, Lee WJ, Kim YT (2004) Paracoccus haeundaensis sp. nov. a gram-negative, halophilic, astaxanthin-producing bacterium. Int I Syst Evol Microbiol 54:1699-1702

Lin Cereghino J, Cregg JM (2000) Heterologous protein expression in the methylotrophic yeast Pichia pastoris. FEMS Microbiol Rev 24:45-66

Miki W, Yamaguchi K, Konosu S (1982) Comparison of carotenoids in the ovaries of marine fish and shellfish. Comp Biochem Physiol 71:7-11

Misawa N, Shimada H (1998) Metabolic engineering for the production of carotenoids in non-carotenogenic bacteria and yeasts. J Biotechnol 59:169-181

Misawa N, Nakagawa M, Kobayashi K, Yamano S, Izawa Y, Nakamura K, Harashima K (1990) Elucidation of the Erwinia uredovora carotenoid biosynthetic pathway by functional analysis of gene products expressed in Escherichia coli. J Bacteriol 172:6704-6712

Misawa N, Satomi Y, Kondo K, Yokoyama A, Kajiwara S, Saito T, Ohtani T, Miki W (1995) Structure and functional analysis of a marine bacterial carotenoid biosynthesis gene cluster and astaxanthin biosynthetic pathway proposed at the gene level. J Bacteriol 177:6575-6584

Miura Y, Kondo K, Saito T, Shimada H, Fraser PD, Misawa N (1998) Production of the carotenoid lycopene, beta-carotene, and astaxanthin in the food yeast Candida utililis. Appl Environ Microbiol 64:1226-1229

Neuman I, Nahum H, Ben-Amotz A (2000) Reduction of exercise-induced asthma oxidative stress by lycopene, a natural antioxidant. Allergy 55:1184-1189

Papp T, Velayos A, Bartók T, Eslava AP, Vágvölgyi C, Iturriaga E (2006) Heterologous expression of astaxanthin biosynthesis genes in Mucor circinelloides. Appl Microbiol Biotechnol 69:526-531

Ukibe K, Hashida K, Yoshida N, Takagi H (2009) Metabolic engineering of Saccharomyces cerevisiae for astaxanthin production and oxidative stress tolerance. Appl Environ Microbiol 75:7205-7211

Verdoes JC, Krubasik P, Sandmann G, van Ooyen AJ (1999) Isolation and functional characterisation of a novel type of carotenoid biosynthetic gene from Xanthophyllonyces dendrorhous. Mol Gen Genet 262:453-461

Verwaal R, Wang J, Meijnen J-P, Visser H, Sandmann G, van den Berg JA, van Ooyen A (2007) High-level production of beta-carotene in Saccharomyces cereviseae by successive transformation with carotenogenic genes from Xanthophyllomyces dendrorhous. Appl Environ Microbiol 73(13):4342-4350

Wade N, Goulter KC, Wilson KJ, Hall MR, Degnan BM (2005) Esterified astaxanthin levels in lobster epithelia correlate with shell colour intensity: potential role in crustacean shell colour formation. Comp Biochem Physiol Biochem Mol Biol 141:307-313

Yamamo S, Ishii T, Nakagawa M, Ikenaga H, Misawa N (1994) Metabolic engineering for production of beta-carotene and lycopene in Saccharomyces cerevisiae. Biosci Biotechnol Biochem 58:1112-1114

Yuan LZ, Rouviere PE, LaRossa RA, Suh W (2006) Chromosomal promoter replacement of the isoprenoid pathway for enhancing carotenoid production in E. coli. Metab Eng 8(1):79-90

doi:10.1186/2191-0855-2-24

Cite this article as: Araya-Garay et al:: Construction of a novel Pichia pastoris strain

for production of xanthophylls. AMB Express 2012 2:24. 